\title{
ВЛИЯНИЕ РЕСУРСОСБЕРЕГАЮЩИХ ТЕХНОЛОГИЙ ОСНОВНОЙ ОБРАБОТКИ ПОЧВЫ НА ЗАСОРЕННОСТЬ ПОСЕВОВ ЯРОВОЙ ПШЕНИЦЫ
}

\author{
V.K. Ivchenko, Z.I. Mikhaylova, \\ A.G. Filippov, S.V. Kokin
}

\section{THE INFLUENCE OF RESOURCE-SAVING TECHNOLOGIES OF BASIC TILLAGE OF THE SOIL ON SPRING WHEAT WEEDINESS}

\begin{abstract}
Ивченко Владимир Кузьмич - д-р с.-х. наук, проф., зав. каф. общего земледелия и защиты растений Красноярского государственного аграрного университета, г. Красноярск.

E-mail:v.f.ivchenko@mail.ru
\end{abstract}

Михайлова Зоя Ивановна - канд. биол. наук, доц. каф. общего земледелия и защиты растений Красноярского государственного аграрного университета, г. Красноярск.

E-mail: zoya2127676@mail.ru

Филиппов Арсений Германович - магистрант кафр. общего земледелия и защиты растений Красноярского государственного аграрного университета, г. Красноярск.

E-mail: senkafilipyan@ mail.ru

Кокин Сергей Викторович - магистрант каф. общего земледелия и защиты растений Красноярского государственного аграрного университета, г. Красноярск.

E-mail: v.f.ivchenko@mail.ru

Цель исследования - изучить влияние различных приемов основной обработки почвы при разных уровнях интенсификации на засоренность посевов яровой пшеницы. Исследование проводилось на землях учхоза «Миндерлинское» Сухобузимского района (Красноярский край) в 2017-2019 г2., выполнялось в севообороте со следующим чередованием культур: сидеральный пар - яровая пшеница - ячмень - кукуруза - яровая пшеница, в звене севооборота кукуруза - яровая пшеница. Засоренность посевов проводилась количественновесовым методом с отражением видового состава сорняков в фазу кущения яровой пшеницы и перед уборкой в 6-кратном повторении рамкой 0,25 м². Математическая обработка результатов исследования проводилась по
Ivchenko Vladimir Kuzmich - Dr. Agr. Sci., Prof., Head, Chair of General Agriculture and Plants Protection, Krasnoyarsk State Agrarian University, Krasnoyarsk.

E-mail: v.f.ivchenko@mail.ru

Mikhaylova Zoya Ivanovna - Cand. Biol. Sci., Assoc. Prof., Chair of General Agriculture and Plants Protection, Krasnoyarsk State Agrarian University, Krasnoyarsk, Krasnoyarsk.

E-mail: zoya2127676@ mail.ru

Filippov Arseny Germanovich - Magistrate Student, Chair of General Agriculture and Plants Protection, Krasnoyarsk State Agrarian University, Krasnoyarsk.

E-mail: senkafilipyan@ mail.ru

Kokin Sergey Victorovich - Magistrate Student, Chair of General Agriculture and Plants Protection, Krasnoyarsk State Agrarian University, Krasnoyarsk.

E-mail:v.f.ivchenko@mail.ru

методике дисперсионного анализа. В борьбе с однодольными и двудольными сорняками применяли гербицид «Пума Голд», КЭ. Объектом исследования являлась яровая пшеница сорта Новосибирская 15. Почвенный покров представлен черноземом выщелоченным, среднемощным, с содержанием гумуса в пахотном слое до 8,0 \%. В фразу кущения яровой пшеницы на неудобренном фоне общая засоренность возрастала от вспашки к минимальным обработкам почвы. После применения гербицида к уборке культуры наиболее засоренными остались посевы на фоне прямого посева в необработанную стерню. При плоскорезной и минимальной обработке количественный состав сорных растений по годам практически не различался. На удобренном фоне массовая до- 
ля сорняков в сравнении с неудобренным фоном несколько возрастает по всем вариантам. $K$ уборке яровой пшеницы наиболее засоренными оставались посевы по минимально обработанной почве и при прямом посеве в необработанную стерню. На второй и третий годы воздельвание яровой пшеницы по плоскорезной, минимальной обработкам почвы и при прямом посеве в необработанную стерню приводит к появлению на вариантах нового видового состава сорных растений. В посевах появляются: Taraxacum vulgare L. (одуванчик), Cannabis ruderalis (конопля сорная), Caleopsis bifida Boenn (жабрей, или пикульник двураздельный), Avena fatua L. (овсюг полевой).

Ключевые слова: обработка почвы, яровая пшеница, минимальная обработка почвы, сорные растения, видовой состав сорняков.

The research objective was to study the efficiency of various methods of the main processing of the soil at different levels of intensification in spring wheat crops weediness. The researches were conducted on the lands of training farm "Minderlinskoe" of Sukhobuzimsky area (Krasnoyarsk Region) in 2017-2019; they were carried out in crop rotation with the following chain of cultures: bare fallow - spring wheat - barley - corn - spring wheat. The study was carried out in crop rotation chain: corn - spring wheat. The study of contamination of crops was carried out by quantitative and weight method with the reflection of specific structure of weeds to the phase of tillering of spring wheat and before harvesting in 6-fold repetition by the frame of 0.25 sq.m. Mathematical processing of the results of the research was carried out by the technique of dispersive analysis. In combating monocotyledonous and two-submultiple weeds "Puma Gold" herbicide, KE was applied. The object of the researches was spring wheat of the variety Novosibirskaya 15. The soil was presented by chernozem lixivious, medium, with the humus content in arable layer to $8.0 \%$. In the phase of tillering of spring wheat on not fertilized background general weediness increased from plowed areas to the minimum processing of the soil areas. After using herbicide in harvesting the culture the most weeded were the crops against direct crops in raw eddish. At flat cutting and minimum processing the quantitative structure of weed plants by years practically did not differ. On fertilized background the mass fraction of weeds in comparison with not fertilized background slightly increased in all the variants. In spring wheat harvesting the most littered were the crops after minimum processed soil and direct crops in raw eddish. For the second and third cultivation of spring wheat on flat cutting, minimum processing of the soil and direct crops in raw eddish led to the emergence of new specific structure of weed plants in the variants. Taraxacum vulgare $L$. (dandelion), Cannabis ruderalis (hemp weed), Caleopsis bifida Boenn (gill, or hemp nettle), Avena fatua $L$. (wild oats) appeared in the crops.

Keywords: tillage, spring wheat, minimal tillage, weeds, species composition of weeds.

Введение. Пшеница как продовольственная культура - один из основных источников энергии для человека и животных. Значение ее как мировой культуры будет непрестанно возрастать, поскольку она представляет собой питательную и экономически выгодную продовольственную культуру, которую можно выращивать в очень разнообразных условиях.

Яровая пшеница по-разному реагирует на почвенно-климатические условия, внесение удобрений и агротехнические приемы. Основным условием получения высокого урожая является правильная агротехника, т. е. своевременное и тщательное проведение агротехнических мероприятий, полностью отвечающих особенностям выращивания культуры.

В системе мер, направленных на повышение урожайности сельскохозяйственных культур, важное место принадлежит обработке почвы. Рациональная обработка почвы улучшает механические, физико-химические и биологические ее свойства, комплексно решает вопросы борьбы с вредителями, болезнями и сорняками, а также водоснабжения и питания культурных растений. Механическая обработка почвы является одним из старейших технологических комплексов в земледелии. Пройдя длинный путь развития от примитивной формы до современных интенсивных приемов, она осталась самым значительным, самым трудоемким и самым проблематичным элементом системы земледелия.

Первостепенная роль в обработке пахотных почв отводится основной обработке, так как это категория обработок наиболее энергоемка и в 
большей степени, чем другие, создает необходимые предпосылки для успешного решения задач, стоящих перед системой обработки почв [2].

Цель исследования: изучение влияния различных приемов основной обработки почвы при разных уровнях интенсификации на засоренность посевов яровой пшеницы.

Материалы и методы исследования. Исследование проводилось на землях учхоза «Миндерлинское» Сухобузимского района в
2017-2019 гг., выполнялось в севообороте со следующим чередованием культур: сидеральный пар - яровая пшеница - ячмень - кукуруза яровая пшеница. Исследование проводилось в звене севооборота: кукуруза - яровая пшеница [4].

Для изучения влияния различных приемов основной обработки почвы на засоренность культуры был заложен полевой опыт. Варианты основной обработки почвы показаны в таблице 1.

Варианты основной обработки почвы при производстве яровой пшеницы

\begin{tabular}{|c|c|c|c|}
\hline \multicolumn{4}{|c|}{ Вариант технологий } \\
\hline Вспашка & $\begin{array}{c}\text { Безотвальная } \\
\text { обработка }\end{array}$ & $\begin{array}{c}\text { Минимальная } \\
\text { обработка }\end{array}$ & $\begin{array}{c}\text { Без основной } \\
\text { обработки }\end{array}$ \\
\hline \multicolumn{4}{|c|}{ Операции по обработке почвы } \\
\hline $\begin{array}{l}\text { 1. 3яблевая отвальная } \\
\text { обработка 20-22 см } \\
\text { (ПЛН-5-35) }\end{array}$ & $\begin{array}{l}\text { 1. Плоскорезное рых- } \\
\text { ление 20-22 см } \\
(\text { КПШ-3,8) }\end{array}$ & $\begin{array}{l}\text { 1. Дискование } \\
\text { на 8-10 см } \\
(\text { БДМ-5,6) }\end{array}$ & - \\
\hline $\begin{array}{l}\text { 2. Ранневесеннее } \\
\text { боронование } \\
(\text { БЗСС-1,0) }\end{array}$ & $\begin{array}{l}\text { 2. Ранневесеннее } \\
\text { боронование } \\
(\text { БЗСС-1,0) }\end{array}$ & $\begin{array}{l}\text { 2. Ранневесеннее } \\
\text { боронование } \\
(\text { БЗСС-1,0) }\end{array}$ & - \\
\hline $\begin{array}{l}\text { 3. Посев } \\
\text { Агратор 4,8 } \\
\text { (без аммиачной селит- } \\
\text { ры и с аммиачной се- } \\
\text { литрой } \\
1 \text { ц/га) }\end{array}$ & $\begin{array}{l}\text { 3. Посев } \\
\text { Агратор } 4,8 \\
\text { (без аммиачной селит- } \\
\text { ры и с аммиачной се- } \\
\text { литрой } 1 \text { ц/га) }\end{array}$ & $\begin{array}{l}\text { 3. Посев } \\
\text { Агратор } 4,8 \\
\text { (без аммиачной се- } \\
\text { литры и с аммиачной } \\
\text { селитрой } 1 \text { ц/га) }\end{array}$ & $\begin{array}{l}\text { 3. Посев } \\
\text { Агратор } 4,8 \\
\text { (без аммиачной се- } \\
\text { литры и с аммиачной } \\
\text { селитрой } 1 \text { ц/га) }\end{array}$ \\
\hline \multicolumn{4}{|c|}{ Oперации по уходу за посевами } \\
\hline \multicolumn{4}{|c|}{ Опрыскивание гербицидом «Пума голд» } \\
\hline \multicolumn{4}{|c|}{ Уборка } \\
\hline
\end{tabular}

Проводились учеты и наблюдения:

1. Засоренность посевов проводилась количественно-весовым методом с отражением видового состава сорняков в фазу кущения яровой пшеницы и перед уборкой в 6-кратном повторении рамкой $0,25 \mathrm{~m}^{2}$.

2. Математическая обработка результатов исследования проводилась по методике дисперсионного анализа [1].
В борьбе с однодольными и двудольными сорняками применяли гербицид «Пума Голд», КЭ. Объектом исследования являлась яровая пшеница сорта Новосибирская 15. Почвенный покров представлен черноземом выщелоченным, среднемощным, с содержанием гумуса в пахотном слое до 8,0 \%. Вегетационные периоды по тепло- и влагообеспеченности в годы исследования значительно отличались от среднемноголетних показателей (табл. 2). 
Метеоусловия в период вегетации яровой пшеницы

Таблица 2

\begin{tabular}{|c|c|c|c|c|c|c|c|c|c|c|c|c|}
\hline \multirow{2}{*}{$\begin{array}{c}\text { Показа- } \\
\text { тель } \\
\end{array}$} & \multicolumn{3}{|c|}{ Май } & \multicolumn{3}{|c|}{ Июнь } & \multicolumn{3}{|c|}{ Июль } & \multicolumn{3}{|c|}{ Август } \\
\hline & 2017 & 2018 & 2019 & 2017 & 2018 & 2019 & 2017 & 2018 & 2019 & 2017 & 2018 & 2019 \\
\hline 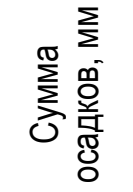 & 28,4 & 29 & 8,4 & 20,5 & 29,1 & 74,1 & 78,9 & 32,5 & 45,4 & 81,2 & 20,7 & 68,9 \\
\hline 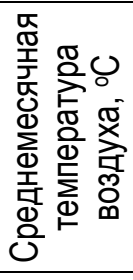 & 10,9 & 8,1 & 9,7 & 20,4 & 20,6 & 18,7 & 19,5 & 18,5 & 19,5 & 16,9 & 18,4 & 18,9 \\
\hline 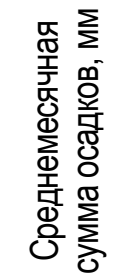 & & 32,0 & & & 44,0 & & & 69,0 & & & 62,0 & \\
\hline 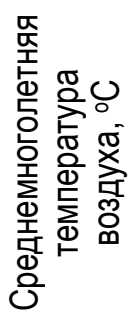 & & 8,0 & & & 15,2 & & & 18,7 & & & 14,9 & \\
\hline
\end{tabular}

Среднемесячная температура воздуха по месяцам вегетации яровой пшеницы была выше многолетних показателей. Июнь в 20172018, а июль в 2018-2019 гг. отличались засушливыми условиями. Количество выпавших осадков в этот период составляло 46,6-66,1 \% от среднемноголетней суммы. Этот период у зерновых культур считается «критическим» по отношению к влаге.

К моменту кущения яровой пшеницы было выявлено 8 видов сорных растений из $6 \mathrm{ce}$ мейств (табл. 3).

По неудобренному фону в наибольшей степени посевы культуры были засорены видами из семейства просовидных и маревых (просо куриное, подмаренник цепкий). Число видов этих двух семейств по годам составляло от 32,0 до $93,8 \%$ от общего количества сорного компонента. Данные сорняки являются теплолюбивыми, и ко времени предпосевных и посевных работ проростки не появились, хотя среднемесячные температуры в мае были выше среднемноголетних показателей. Основная обработка почвы по-своему влияла на засоренность яровой пшеницы в фазе кущения. Наиболее чистыми посевы культуры были на варианте с отвальной вспашкой. Количественный состав по годам изменялся от 9 до 32 шт/M², что ниже экономического порога вредоносности (ЭПВ). В 2017 г. наибольшей засоренностью отличались посевы яровой пшеницы по плоскорезному фону (92 шт/м²), а в 2019 г. - по минимальным обработкам (110 шт/м²). Засоренность в другие годы по плоскорезному фону, минимально обработанной почве и на варианте без основной обработки почвы не изменялась и была выше ЭПВ (кроме 2018 г.). Следует отметить, что в течение трех лет применение плоскореза, дискатора и при прямом посеве яровой пшеницы, возделываемой после кукурузы, не наблюдалось закономерности в увеличении сорняков. Скорее всего, количество сорняков в этот период зависело от погодных условий второй половины мая и первой декады июня, а также засоренности предшественника. 
Количественный и видовой состав сорных растений в зависимости от основной обработки почвы (неудобренный фон), шт/м²

\begin{tabular}{|c|c|c|c|c|c|c|c|c|}
\hline \multirow{3}{*}{$\begin{array}{c}\text { Видовой состав } \\
\text { сорняков }\end{array}$} & \multicolumn{8}{|c|}{ Обработка почвы (неудобренный фон) } \\
\hline & \multicolumn{2}{|c|}{$\begin{array}{c}\text { Вспашка } \\
\text { (контроль) }\end{array}$} & \multicolumn{2}{|c|}{$\begin{array}{c}\text { Плоскорезная } \\
\text { обработка }\end{array}$} & \multicolumn{2}{|c|}{$\begin{array}{l}\text { Обработка } \\
\text { дискатором }\end{array}$} & \multicolumn{2}{|c|}{$\begin{array}{c}\text { Прямой } \\
\text { посев }\end{array}$} \\
\hline & $2017 / 2018$ & 2019 & $2017 / 2018$ & 2019 & $2017 / 2018$ & 2019 & $2017 / 2018$ & 2019 \\
\hline $\begin{array}{l}\text { Cirsium arvense Scop. } \\
\text { Осот розовый }\end{array}$ & 0 & 0 & $2 / 1$ & 3 & $1 / 2$ & 3 & $1 / 4$ & 6 \\
\hline $\begin{array}{l}\text { Convolvulus arvensis L. } \\
\text { Вьюнок полевой }\end{array}$ & $2 / 2$ & 2 & $8 / 0$ & 4 & $4 / 5$ & 6 & $4 / 4$ & 9 \\
\hline $\begin{array}{l}\text { Erodium cicutarium } \\
\text { Подмаренник цепкий }\end{array}$ & $20 / 1$ & 1 & $30 / 1$ & 2 & $30 / 3$ & 5 & $30 / 5$ & 7 \\
\hline $\begin{array}{l}\text { Echinochloa crusgalli } \\
\text { Просо куриное }\end{array}$ & $10 / 2$ & 5 & $52 / 20$ & 22 & $41 / 11$ & 16 & $25 / 3$ & 10 \\
\hline $\begin{array}{l}\text { Taraxacum vulgare L. } \\
\text { Одуванчик }\end{array}$ & 0 & 0 & 0 & 0 & 0 & 0 & 0 & 3 \\
\hline $\begin{array}{l}\text { Cannabis ruderalis } \\
\text { Конопля сорная }\end{array}$ & 0 & 0 & 0 & 1 & $0 / 1$ & 10 & $0 /$ & 4 \\
\hline $\begin{array}{l}\text { Caleopsis bifida Boenn } \\
\text { Жабрей, или пикульник } \\
\text { двураздельный }\end{array}$ & $0 / 1$ & 2 & $0 / 1$ & 2 & $0 / 4$ & 40 & $0 / 2$ & 5 \\
\hline $\begin{array}{l}\text { Avena fatua L. } \\
\text { Овсюг обыкновенный }\end{array}$ & $0 / 3$ & 5 & $0 / 5$ & 6 & $0 / 3$ & 30 & $0 / 7$ & 8 \\
\hline Всего & $32 / 9$ & 15 & $92 / 28$ & 40 & $76 / 29$ & 110 & $60 / 25$ & 52 \\
\hline $\mathrm{HCP}_{095}$ & & & & 1 & & & & \\
\hline
\end{tabular}

На фоне применения аммиачной селитры (1 ц/га в фризическом весе) общая засоренность в фразу кущения зерновых практически во все годы была выше на 9-32 сорняка в сравнении с неудобренным фоном. Возрастание сорняков по отдельным видам не отмечено, шло общее возрастание по каждому виду. В зависимости от обработки почвы засоренность изменялась следующим образом. На второй и третий год по плоскорезному фону, минимально обработанной почве и при прямом посеве выявлено еще четыре вида сорных растений: Avena fatua L. (овсюг обыкновенный); Cannabis ruderalis (конопля сорная); Caleopsis bifida Boenn. (жабрей, или пикульник двураздельный); Taraxacum vulgare L. (одуванчик обыкновенный). На третий год возделывания яровой пшеницы по минимальной и нулевой технологии количество последних видов сорных растений выше, чем в первый и второй годы (табл. 4). Засоренность посевов яровой пшеницы, возделываемой по отвальной вспашке (по двум фонам), достоверно ниже, чем по безотвальной, минимальной обработкам и при прямом посеве [3]. 
Количественный и видовой состав сорных растений в зависимости от основной обработки почвы (удобренный фон), шт/M ${ }^{2}$

\begin{tabular}{|c|c|c|c|c|c|c|c|c|}
\hline \multirow{3}{*}{$\begin{array}{c}\text { Видовой состав } \\
\text { сорняков }\end{array}$} & \multicolumn{8}{|c|}{ Обработка почвы (удобренный фрон) } \\
\hline & \multicolumn{2}{|c|}{$\begin{array}{c}\text { Вспашка } \\
\text { (контроль) }\end{array}$} & \multicolumn{2}{|c|}{$\begin{array}{c}\text { Плоскорезная } \\
\text { обработка }\end{array}$} & \multicolumn{2}{|c|}{$\begin{array}{l}\text { Обработка } \\
\text { дискатором }\end{array}$} & \multicolumn{2}{|c|}{$\begin{array}{l}\text { Прямой } \\
\text { посев }\end{array}$} \\
\hline & 2017/18 & 2019 & 2017/18 & 2019 & $2017 / 18$ & 2019 & $2017 / 18$ & 2019 \\
\hline $\begin{array}{l}\text { Cirsium arvense Scop. } \\
\text { Осот розовый }\end{array}$ & $0 / 1$ & 2 & $1 / 1$ & 2 & $2 / 2$ & 3 & $2 / 4$ & 4 \\
\hline $\begin{array}{l}\text { Convolvulus arvensis L. } \\
\text { Вьюнок полевой }\end{array}$ & $4 / 2$ & 3 & $8 / 4$ & 5 & $6 / 5$ & 6 & $10 / 5$ & 7 \\
\hline $\begin{array}{l}\text { Erodium cicutarium } \\
\text { Подмаренник цепкий }\end{array}$ & $30 / 4$ & 5 & $40 / 5$ & 7 & $30 / 5$ & 7 & $50 / 6$ & 8 \\
\hline $\begin{array}{l}\text { Echinochloa crusgalli } \\
\text { Просо куриное }\end{array}$ & $15 / 3$ & 5 & $20 / 29$ & 35 & $25 / 12$ & 15 & $30 / 8$ & 18 \\
\hline $\begin{array}{l}\text { Taraхасum vulgare L. } \\
\text { Одуванчик }\end{array}$ & $0 / 0$ & 0 & $0 / 0$ & 1 & $0 / 3$ & 4 & 4 & 5 \\
\hline $\begin{array}{l}\text { Cannabis ruderalis } \\
\text { Конопля сорная }\end{array}$ & $0 / 0$ & 1 & $0 / 2$ & 3 & $0 / 4$ & 5 & $0 / 2$ & 6 \\
\hline $\begin{array}{l}\text { Caleopsis bifida Boenn. } \\
\text { Жабрей, или пикульник } \\
\text { двураздельный }\end{array}$ & $0 / 2$ & 3 & $0 / 3$ & 5 & $0 / 4$ & 6 & $0 / 3$ & 7 \\
\hline $\begin{array}{l}\text { Avena fatua L. } \\
\text { Овсюг обыкновенный }\end{array}$ & $0 / 5$ & 5 & $0 / 5$ & 6 & $0 / 5$ & 7 & $0 / 7$ & 9 \\
\hline Всего & $49 / 17$ & 24 & $69 / 49$ & 64 & $63 / 40$ & 53 & $92 / 39$ & 64 \\
\hline $\mathrm{HCP}_{095}$ & & & & & 14 & & & \\
\hline
\end{tabular}

Минимализация затрат и энергосбережение, основанные на применении минимальных и нулевых обработок почвы, требуют применения химических средств защиты от сорного компонента. В исследовании в целях борьбы с однодольными и двудольными сорняками применялся гербицид «Пума Голд», КЭ, с нормой расхода препарата 1,0 л/га.

По отвальной вспашке на неудобренном фоне общее количество малолетних сорных растений к уборке по годам колебалось от 5 до 8 шт/M², что ниже ЭПВ. Многолетние сорняки отсутствовали. В первый год возделывания яровой пшеницы по плоскорезному фону к уборке сорняков было 18 шт/м². На второй год количество сорняков несколько снизилось, но стали появляться многолетники. На третий год применение плоскорезной обработки приводит к увеличению засоренности до 33 шт/ $\mathrm{M}^{2}$ не только за счет увеличения малолетних сорных растений, но и многолетних. По минимально обработанной почве (дискование на 8-10 см) в первый год засоренность оставалась на уровне плоскорезного фона. На второй и третий год засоренность увеличилась за счет многолетних сорных растений и тех видов, которые отсутствовали в первый год возделывания яровой пшеницы по вышеприведенной технологии. Самая высокая засоренность яровой пшеницы к уборке оставалась при возделывании ее при прямом посеве. На второй и третий год без основной обработки почвы засоренность возрастает до 42-55 шт/м². В эти годы здесь наблюдается самая высокая засоренность осотом розовым, вьюнком полевым и одуванчиком (табл. 5). 
Видовой и количественный состав сорных растений в посевах яровой пшеницы после применения гербицида (неудобренный фон), шт/м²

\begin{tabular}{|c|c|c|c|c|c|c|c|c|}
\hline \multirow{3}{*}{$\begin{array}{c}\text { Видовой состав } \\
\text { сорняков }\end{array}$} & \multicolumn{8}{|c|}{ Обработка почвы (неудобренный фон) } \\
\hline & \multicolumn{2}{|c|}{ Вспашка (контроль) } & \multicolumn{2}{|c|}{$\begin{array}{c}\text { Плоскорезная } \\
\text { обработка }\end{array}$} & \multicolumn{2}{|c|}{$\begin{array}{l}\text { Обработка } \\
\text { дискатором }\end{array}$} & \multicolumn{2}{|c|}{ Прямой посев } \\
\hline & $\begin{array}{l}2017 / \\
2018\end{array}$ & 2019 & $\begin{array}{l}2017 / \\
2018\end{array}$ & 2019 & $\begin{array}{l}2017 / \\
2018\end{array}$ & 2019 & $\begin{array}{l}2017 / \\
2018\end{array}$ & 2019 \\
\hline $\begin{array}{l}\text { Cirsium arvense Scop. } \\
\text { Осот розовый }\end{array}$ & $0 / 0$ & 0 & $0 / 0$ & 1 & $0 / 1$ & 2 & $0 / 1$ & 4 \\
\hline $\begin{array}{l}\text { Convolvulus arvensis L. } \\
\text { Вьюнок полевой }\end{array}$ & $0 / 0$ & 0 & $0 / 7$ & 8 & $0 / 3$ & 5 & $0 / 4$ & 6 \\
\hline $\begin{array}{l}\text { Erodium cicutarium } \\
\text { Подмаренник цепкий }\end{array}$ & $4 / 0$ & 0 & 812 & 5 & $7 / 3$ & 7 & $10 / 0$ & 2 \\
\hline $\begin{array}{l}\text { Echinochloa crusgalli } \\
\text { Просо куриное }\end{array}$ & $4 / 8$ & 5 & 1011 & 6 & $12 / 11$ & 15 & $18 / 29$ & 30 \\
\hline $\begin{array}{l}\text { Taraxacum vulgare L. } \\
\text { Одуванчик }\end{array}$ & $0 / 0$ & 0 & $0 / 1$ & 2 & $0 / 1$ & 2 & $0 / 2$ & 3 \\
\hline $\begin{array}{l}\text { Cannabis ruderalis } \\
\text { Конопля сорная }\end{array}$ & $0 / 0$ & 0 & $0 / 1$ & 3 & $0 / 1$ & 3 & $0 / 0$ & 2 \\
\hline $\begin{array}{l}\text { Caleopsis bifida Boenn. } \\
\text { Жабрей, или пикульник } \\
\text { двураздельный }\end{array}$ & $0 / 0$ & 0 & $0 / 1$ & 3 & $0 / 1$ & 3 & $0 / 2$ & 3 \\
\hline $\begin{array}{l}\text { Avena fatua } \mathrm{L} . \\
\text { Овсюг полевой }\end{array}$ & $0 / 0$ & 0 & $0 / 2$ & 5 & $0 / 1$ & 4 & $0 / 4$ & 5 \\
\hline Всего & $8 / 8$ & 5 & $18 / 15$ & 33 & $19 / 22$ & 41 & $28 / 42$ & 55 \\
\hline $\mathrm{HCP}_{095}$ & & & & & & & & \\
\hline
\end{tabular}

По удобренному предшественнику при отвальной вспашке количество сорных растений к уборке на второй и третий год было несколько выше, чем по неудобренному. Основными засорителями были: просо куриное, подмаренник цепкий, овсюг обыкновенный. Из многолетних сорных растений в 2019 г. посевы были засорены вьюнком полевым. Засоренность посевов яровой пшеницы к уборке при использовании плоскорезной обработки почвы в качестве основной от фона не зависела. Минимальная обработка почвы также мало влияла на засорен- ность удобренного и неудобренного фонов. На второй и третий год (2018-2019 гг.) применения прямого посева культуры в необработанную стерню по удобренному фону засоренность была несколько выше, чем по неудобренному фону. Также следует отметить, что прямой посев, минимальная и плоскорезная обработки почвы в качестве основной на второй и третий годы приводят к появлению на полях одуванчика, конопли сорной, жабрея и овсюга обыкновенного (табл. 6). 
Видовой и количественный состав сорных растений после применения гербицида

Таблица 6 (удобренный фон), шт/м²

\begin{tabular}{|c|c|c|c|c|c|c|c|c|}
\hline \multirow{3}{*}{$\begin{array}{c}\text { Видовой состав } \\
\text { сорняков }\end{array}$} & \multicolumn{8}{|c|}{ Количество сорняков к уборке (удобренный фон) } \\
\hline & \multicolumn{2}{|c|}{$\begin{array}{c}\text { Вспашка } \\
\text { (контроль) }\end{array}$} & \multicolumn{2}{|c|}{$\begin{array}{c}\text { Плоскорезная } \\
\text { обработка }\end{array}$} & \multicolumn{2}{|c|}{$\begin{array}{l}\text { Обработка } \\
\text { дискатором }\end{array}$} & \multicolumn{2}{|c|}{ Прямой посев } \\
\hline & $2017 / 2018$ & 2019 & $2017 / 2018$ & 2019 & $2017 / 2018$ & 2019 & $2017 / 2018$ & 2019 \\
\hline $\begin{array}{l}\text { Cirsium arvense Scop. } \\
\text { Осот розовый }\end{array}$ & $0 / 0$ & 0 & $0 / 0$ & 1 & $0 / 2$ & 3 & $0 / 2$ & 3 \\
\hline $\begin{array}{l}\text { Convolvulus arvensis L. } \\
\text { Вьюнок полевой }\end{array}$ & $0 / 0$ & 2 & $0 / 6$ & 8 & $0 / 3$ & 6 & $0 / 5$ & 6 \\
\hline $\begin{array}{l}\text { Erodium cicutarium } \\
\text { Подмаренник цепкий }\end{array}$ & $4 / 2$ & 5 & $8 / 3$ & 5 & $7 / 6$ & 8 & $10 / 0$ & 9 \\
\hline $\begin{array}{l}\text { Echinochloa crusgalli } \\
\text { Просо куриное }\end{array}$ & $4 / 6$ & 8 & $10 / 2$ & 4 & $12 / 12$ & 14 & $18 / 30$ & 35 \\
\hline $\begin{array}{l}\text { Taraxacum vulgare L. } \\
\text { Одуванчик }\end{array}$ & $0 / 0$ & 0 & $0 / 2$ & 3 & $0 / 2$ & 3 & $0 / 3$ & 3 \\
\hline $\begin{array}{l}\text { Cannabis ruderalis } \\
\text { Конопля сорная }\end{array}$ & $0 / 0$ & 1 & $0 / 2$ & 5 & $0 / 2$ & 5 & $0 / 2$ & 3 \\
\hline $\begin{array}{l}\text { Caleopsis bifida Boenn. } \\
\text { Жабрей, или пикульник } \\
\text { двураздельный }\end{array}$ & $0 / 2$ & 3 & $0 / 1$ & 5 & $0 / 1$ & 3 & $0 / 2$ & 4 \\
\hline $\begin{array}{l}\text { Avena fatua } \mathrm{L} . \\
\text { Овсюг полевой }\end{array}$ & $0 / 2$ & 4 & $0 / 2$ & 4 & $0 / 2$ & 5 & $0 / 6$ & 8 \\
\hline Всего & $8 / 12$ & 23 & $18 / 18$ & 35 & $19 / 30$ & 47 & $28 / 50$ & 71 \\
\hline $\mathrm{HCP}_{095}$ & & & & & 12 & & & \\
\hline
\end{tabular}

Заключение. В фазу кущения яровой пшеницы на неудобренном фоне общая засоренность возрастала от вспашки к минимальным обработкам почвы. После применения гербицида к уборке культуры наиболее засоренными остались посевы на фоне прямого посева в необработанную стерню. При плоскорезной и минимальной обработке количественный состав сорных растений по годам практически не различался. На удобренном фоне массовая доля сорняков в сравнении с неудобренным фоном несколько возрастает по всем вариантам. К уборке яровой пшеницы наиболее засоренными оставались посевы по минимально обработанной почве и при прямом посеве в необработанную стерню. На второй и третий годы возделывания яровой пшеницы по плоскорезной, минимальной обработкам почвы и при прямом посеве в необработанную стерню приводит к появлению на вариантах нового видового состава сорных растений. В посевах появляются: Taraxacum vulgare L. (одуванчик), Cannabis ruderalis (конопля сорная), Caleopsis bifida Boenn. (жабрей, или пикульник двураздельный), Avena fatua L. (овсюг полевой).

\section{Литература}

1. Доспехов Б.А. Методика полевого опыта. М.: Агропромиздат, 1985. 352 с.

2. Едимеичев Ю.Ф., Бекетова О.А. Агроэкологические основы оптимизации системы обработки почвы в Красноярском крае: учеб. пособие. Красноярск, 2019. 200 с.

3. Ивченко В.К., Михайлова З.И. Влияние различных обработок почвы и средств интен- 
сификации на продуктивность зерновых культур // Вестник КрасГАУ. 2017. № 4. C. 3-10.

4. Ивченко В.К., Михайлова З.И. Некоторые пути снижения затрат ископаемой энергии на черноземах выщелоченных Красноярской лесостепи // Вестник КрасГАУ. 2019. № 4. C. 3-19.

5. Михайлова 3.И., Михайлов А.А., Вакуленко О.В. Влияние способов обработки почвы на продуктивность зерновых культур // Вестник КрасГАУ. 2016. № 4. С. 10-15.

\section{Literatura}

1. Dospehov B.A. Metodika polevogo opyta. M.: Agropromizdat, 1985. $352 \mathrm{~s}$.
2. Edimeichev Ju.F., Beketova O.A. Agrojekologicheskie osnovy optimizacii sistemy obrabotki pochvy v Krasnojarskom krae: ucheb. posobie. Krasnojarsk, 2019. $200 \mathrm{~s}$.

3. Ivchenko V.K., Mihajlova Z.I. Vlijanie razlichnyh obrabotok pochvy i sredstv intensifykacii na produktivnost' zernovyh kul'tur // Vestnik KrasGAU. 2017. № 4. S. 3-10.

4. Ivchenko V.K., Mihajlova Z.I. Nekotorye puti snizhenija zatrat iskopaemoj jenergii na chernozemah vyshhelochennyh Krasnojarskoj lesostepi // Vestnik KrasGAU. 2019. № 4. S. 3-19.

5. Mihajlova Z.I., Mihajlov A.A., Vakulenko O.V. Vlijanie sposobov obrabotki pochvy na produktivnost' zernovyh kul'tur // Vestnik KrasGAU. 2016. № 4. S. 10-15. 